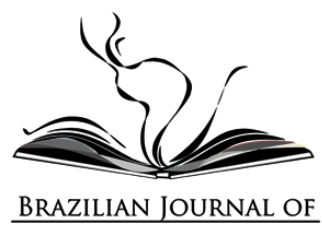

\title{
CAPITALISMO: SEM RIVAIS E NA ENCRUZILHADA'
}

\author{
CAPITALISMO: SIN RIVALES Y EN LA ENCRUCIJADA \\ CAPITALISM: WITHOUT RIVALS AND AT A CROSSROADS
}

Tiago Oliveira (iD) 2

Universidade de Coimbra, Portugal

\begin{abstract}
Resumo: Em "Capitalismo Sem Rivais, o futuro do sistema que domina o mundo", Branko Milanovic reflete sobre o sistema econômico em que vivemos e o confronto atual entre seus dois modelos: o capitalismo meritocrático liberal e o capitalismo político. A partir de uma leitura original da história econômica contemporânea e da reflexão sobre o futuro do capitalismo, o autor discute com rigor os principais problemas que afligem as sociedades contemporâneas como as desigualdades, as políticas sociais, as migrações, a corrupção e a globalização, e propõe medidas para enfrentá-los, o que torna a sua obra especialmente relevante para países de níveis de desenvolvimento mais baixos, a exemplo dos latino-americanos.
\end{abstract}

Palavras-chave: Capitalismo; Desigualdades; Globalização; Políticas sociais, Migração.

Resumen: En "Capitalismo, Nada Más: el futuro del sistema que domina el mundo", Branko Milanovic reflexiona sobre el sistema económico en el que vivimos y el enfrentamiento actual entre sus dos modelos: el capitalismo meritocrático liberal y el capitalismo político. A partir de una lectura original de la historia económica contemporánea y una reflexión sobre el futuro del capitalismo, el autor analiza con rigor los principales problemas que preocupan a las sociedades contemporáneas como las desigualdades, las políticas sociales, la migración, la corrupción y la globalización, y propone medidas para enfrentarlos, lo que hace que su trabajo sea de especial relevancia para países con menor nivel de desarrollo, como los países de América Latina.

\footnotetext{
${ }^{1}$ Este trabalho é financiado por fundos nacionais através da FCT - Fundação para a Ciência e a Tecnologia, I.P. (Portugal), no âmbito do projeto PTDC/DIR-OUT/32096/2017 - "ART 63: O direito à segurança social e a crise - 0 retrocesso social como normalização do estado de exceção financeira".

${ }^{2}$ Investigador do Centro de Estudos Sociais (CES) da Universidade de Coimbra. E-mail: tiagooliveira@ces.uc.pt
}

Cadernos Prolam/USP-Brazilian Journal of Latin American Studies, v. 20, n. 40, p. 263-275, out. 2021 Edição especial: Trabalho e proteção social na América Latina: desenvolvimentos recentes e os desafios diante da crise pandêmica. ISSN: 1676-6288 
Palabras-claves: Capitalismo; Desigualdades; Globalización; Políticas sociales; Migración.

Abstract: In "Capitalism, Alone: the future of the system that rules the world", Branko Milanovic reflects on the economic system in which we live in and the current confrontation between its two economic models: the liberal meritocratic capitalism and the political capitalism. Based on an original reading of contemporary economic history and a reflection on the future of capitalism, the author precisely discusses the main issues of concern to contemporary societies such as inequality, social policies, migration, corruption, and globalization, and proposes measures to address them, which makes his work particularly relevant for countries with lower levels of development, such as Latin American countries.

Keywords: Capitalism; Inequalities; Globalization; Social policies; Migration.

DOI:10.11606/issn.1676-6288.prolam.2021.186291

Nos dias atuais, as desigualdades de renda e de riqueza aproximam-se em muitos países de patamares poucas vezes atingidos, resultado de uma longa trajetória de alta iniciada no último terço do século passado. A percepção social dos malefícios causados por níveis extremados de desigualdades esteve na origem de inúmeros protestos pelo mundo na década passada, renovando o interesse de intelectuais e pesquisadores sobre o tema, evidenciado pela vasta e profícua produção bibliográfica publicada no período recente.

De acordo com o Banco Mundial, apesar da concentração distributiva dos rendimentos do trabalho não ser hoje um problema exclusivo dos países menos desenvolvidos, nota-se que dos dez países mais desiguais do mundo, oito situam-se na América Latina ${ }^{3}$, o que faz do reavivamento dessa discussão especialmente relevante para os países localizados nesta região.

\footnotetext{
${ }^{3}$ São eles, apresentados por ordem decrescente do índice de Gini, o mais tradicional indicador de desigualdade de renda: Brasil, Panamá, Colômbia, Honduras, Paraguai, Costa Rica, Equador e Bolívia. Dados para 2017 e disponíveis em: https://data.worldbank.orgl.
} 
Nesse contexto, Branko Milanovic destaca-se como um dos principais autores dedicados aos estudos das desigualdades econômicas. Atualmente, o economista sérvio-americano é professor visitante da Universidade da Cidade de Nova York e pesquisador sênior no Luxembourg Income Study Center, após ter coordenado por mais de duas décadas o departamento de pesquisa do Banco Mundial. É autor de inúmeros estudos e reflexões sobre o tema publicados em livros traduzidos em diversos idiomas e nos mais prestigiados periódicos especializados do mundo.

Em sua mais recente obra intitulada "Capitalismo Sem Rivais: o futuro do sistema que domina o mundo", publicada em 2020 no Brasil pela Editora Todavia, Milanovic reflete sobre os temas que mais inquietam as sociedades atuais como as desigualdades, as políticas sociais, as migrações, a corrupção e a globalização, oferecendo uma interpretação original dos problemas que assolam o capitalismo contemporâneo, assim como propostas para enfrentá-las.

No curto primeiro capítulo, denominado "Os contornos do mundo pós-Guerra Fria", Milanovic defende a tese que dá título ao livro, avançando com a constatação de que hoje o capitalismo impõe-se como único sistema socioeconômico existente no mundo. E mais, segundo o autor, a sua vitória em escala mundial a partir da dissolução da União Soviética deu origem a dois tipos diferentes de capitalismo, o capitalismo meritocrático liberal e o capitalismo político, representados como tipos ideais, respectivamente, pelos Estados Unidos e pela China.

Parece-me pouco questionável que a história da economia mundial desde a derrocada do comunismo soviético vem sendo tecida a partir da expansão e dominação do sistema capitalista. Entretanto não me parece razoável supor - e esta é uma das principais críticas que pode ser endereçada para o livro "Capitalismo Sem Rivais" - que o sistema capitalista cindiu-se tão somente em dois modelos diferentes a partir da queda do muro de Berlim. Tampouco parece-me adequado argumentar que esses 
dois modelos tratar-se-iam apenas de pontos extremos de uma reta onde os países poderiam ser perfilados mais à direita ou mais à esquerda, de acordo com sua maior ou menor similitude a cada um dos modelos.

Ao contrário, ao nos questionarmos quão parecidos são os capitalismos existentes na Suécia, no Brasil e em Portugal, por exemplo, é incontornável concluirmos que há hoje uma variedade bem maior de capitalismos, caracterizados, como propõe Bruno Amable (2005), por formas institucionais específicas e complementaridades institucionais muito particulares que dão origem a modelos para além dos dois abordados em "Capitalismos Sem Rivais".

Os dois próximos capítulos do livro são dedicados a cada um dos tipos de capitalismo atualmente existentes, de acordo com a tipologia proposta pelo autor. No segundo capítulo, o capitalismo meritocrático liberal é caracterizado como um modelo de organização econômica que apresenta uma tendência de elevação da apropriação da renda pelo capital, cuja posse concentra-se em uma parcela pequena da sociedade, que se constitui em sua fração mais rica.

Outra característica é a elevada recorrência de casamentos entre homens e mulheres ricos (homogamia), assim como a forte correlação existente entre os rendimentos de pais e filhos, o que revela a sua alta capacidade de perpetuação intergeracional das desigualdades, de resto, uma preocupação que Milanovic compartilha com outros autores dedicados ao tema, como Joseph Stiglitz, laureado com o prêmio Nobel de economia em 2001, e Thomas Piketty, economista francês que ganhou destaque internacional com seu livro "O Capital no século XXI", publicado em 20134. A única característica, entretanto, exclusivamente presente no capitalismo meritocrático liberal, que o distinguiria de modelos pretéritos ${ }^{5}$, é a apropriação pelos mesmos indivíduos das rendas mais elevadas do capital e do trabalho, potencializando as desigualdades econômicas e tornando o seu enfrentamento ainda mais difícil.

\footnotetext{
${ }^{4}$ Ver, por exemplo, as suas mais recentes obras: Stiglitz (2019) e Piketty (2020).

${ }^{5}$ Para Milanovic, dois outros tipos de capitalismo precederam historicamente o capitalismo meritocrático liberal: o capitalismo clássico e o capitalismo social-democrata.
} 
Para Milanovic, combater as notáveis desigualdades acumuladas ao longo dos últimos quarenta anos exigiria novas políticas sociais. Porquanto, revigorar os pilares de sustentação do capitalismo social-democrata sindicatos fortes, educação massiva, impostos elevados e importantes transferências sociais - seria dificilmente exequível ou não mais surtiria os mesmos efeitos positivos de outrora: seja porque o mercado de trabalho transformou-se radicalmente no período; ou porque há limites à expansão dos níveis de educação, especialmente em países que já possuem uma população com muitos anos de estudo; ou mesmo porque a globalização e a alta mobilidade do capital e do trabalho, assim como as resistências políticas hoje existentes, constituem em obstáculos importantes para o aumento de impostos ou de transferências sociais.

É preciso - argumenta Milanovic - mirar um capitalismo mais igualitário, baseado numa dotação menos assimétrica de capital e de qualificação entre os indivíduos. Para tanto, "Capitalismo Sem Rivais" apresenta propostas que visam uma redução da concentração do capital, de um lado, e o combate às desigualdades ligadas ao trabalho, de outro. No primeiro caso, propõe políticas fiscais que favoreceriam a propriedade de ativos financeiros pelos pequenos e médios investidores em detrimento dos grandes investidores; a criação de programas ou de projetos de incentivo no nível das empresas que aumentariam a participação acionária dos empregados; e, por último, a taxação de herança ou da riqueza que distribuiriam melhor o acesso ao capital, utilizando as receitas fiscais para conceder algum capital à população jovem adulta. No campo do combate às desigualdades ligadas ao trabalho, sugere-se nivelar os padrões de ensino entre as escolas, o que tornaria mais homogêneo os ganhos que as pessoas com o mesmo nível de educação obtêm de sua formação.

Nesse cenário, o autor mostra-se cético quanto ao futuro do Estado social. Lembra-nos que os países desenvolvidos, submetidos a níveis elevados de concentração da renda e a intensos fluxos migratórios, defrontam-se atualmente com dois tipos de seleção adversa: no plano 
nacional, países mais desiguais geram incentivos para que os mais ricos busquem soluções privadas para a cobertura dos riscos sociais aos quais se sujeitam, erodindo a base fiscal de sustentação do Estado social; no plano internacional, os países com sistemas de proteção social mais abrangentes são mais propensos a atrair imigrantes pouco qualificados, de menor capacidade contributiva e maior demanda pelos serviços públicos, afugentando os nacionais do sistema. Para o autor, os países ricos deveriam implementar as medidas já acima referidas acompanhadas pelo aumento de restrições de acesso à cidadania e ao Estado social pelo trabalhador imigrante, aspecto que o autor retoma de sua obra anterior ${ }^{6}$, mas que somente desenvolve e aprofunda no capítulo 4.

O segundo capítulo é finalizado com um alerta para a desproporcional influência política dos ricos, preocupação que o autor compartilha com seus pares anteriormente mencionados. Ao financiar os partidos políticos e controlar as campanhas eleitorais, os ricos teriam a capacidade de moldar em benefício próprio a agenda pública e as políticas implementadas, pelo que contribuem, conjuntamente com um sistema de ensino privado e caro, para a perpetuação de uma muito diminuta elite econômica no cume da estratificação social.

Milanovic propõe no segundo capítulo, entre outros aspectos, um paradigma de proteção social e de combate às desigualdades, no nosso entender, pouco efetivo diante da realidade multifacetada do capitalismo global, especialmente se se consideram os países mais pobres, como a maior parte dos países da América Latina. Em sua visão, como não há alternativas reformistas viáveis para uma reinvenção do Estado social na quadratura atual da história, resta o caminho da democratização do acesso ao capital e à educação como meio de enfrentamento das gritantes e crescentes desigualdades econômicas dos dias atuais.

Nesse ponto, ele se posiciona em um campo distinto ao ocupado por Joseph Stiglitz e Thomas Piketty, que buscaram em suas obras mais recentes reafirmar e defender a importância do Estado social no combate

${ }^{6}$ Ver Milanovic (2016). 
às desigualdades. Para o primeiro, uma economia mais dinâmica e inovadora, com preocupação ambiental, não pode estar dissociada da busca por maior segurança econômica, proteção social e justiça social. Destarte, o pleno emprego e a geração de emprego decente, uma tributação mais progressiva, amplas transferências sociais e despesas públicas robustas ainda consistiriam em pilares básicos de uma estratégia de desenvolvimento para o século XXI (STIGLITZ, 2019). Thomas Piketty, por sua vez, defende que as desigualdades que assolam as sociedades atuais exigem uma intervenção política radical, que busque a construção de um socialismo participativo fundado na propriedade social e temporária do capital. Nesse contexto, além da necessidade de se alcançar uma melhor partilha do poder nas empresas entre trabalhadores e seus empregadores, manter-se-ia a centralidade na agenda governamental dos impostos progressivos sobre sucessões, rendimentos e propriedade, como fontes de financiamento do Estado social e da despesa pública em geral (PIKETTY, 2020).

Deste modo, parece-me de fato precipitado, e mesmo indesejável, abandonar, como o faz Milanovic, o Estado Social como alternativa de desenvolvimento ao neoliberalismo. Não só porque ele continua existindo sob diversas configurações nacionais, mas também porque continua a ser uma resposta válida para os problemas sociais do século $\mathrm{XXI}$, dentre os quais as elevadas desigualdades econômicas?

Em oposição ao capitalismo meritocrático liberal, o autor analisa no terceiro capítulo o capitalismo político, presente em países colonizados, formalmente ou não, como a China, e que vivenciaram revoluções comunistas que permitiram, com variados graus de êxito, que sociedades atrasadas transitassem do feudalismo para um capitalismo endógeno.

A interpretação da história do desenvolvimento dos países de capitalismo retardatário oferecida por Milanovic tem como ponto de partida a constatação de que o subdesenvolvimento e a dominação

\footnotetext{
${ }^{7}$ Aconselha-se a leitura de Ramaux (2012).
} 
estrangeira são condições que estiveram presentes nos países do chamado terceiro mundo no início do século XX, mas não nos países de capitalismo avançado, quando em semelhante estágio de desenvolvimento. Logo, os países do terceiro mundo necessitariam de uma dupla revolução: a social, que mirasse a transformação das relações de produção então dominantes; e a política, com o objetivo de pôr fim à dominação estrangeira. E somente os partidos comunistas, e o controle exercido por eles sobre um Estado forte e autoritário, reuniam condições - ideológicas e organizativas - para levar adiante essa missão revolucionária.

Mas o que o autor entende por capitalismo político? Para ele, o capitalismo político possui três características e duas contradições sistêmicas. A primeira característica é a presença de uma burocracia muito eficaz e uma tecnocracia competente à frente do sistema que compartilham o objetivo de implementar políticas públicas em prol de um crescimento econômico forte e duradouro, base de legitimação do modelo. A ausência de um Estado de direito é a sua segunda característica. Por fim, a dupla capacidade do Estado de ser movido pelos interesses nacionais e de controlar o setor privado, ou seja, o seu caráter autônomo, constitui-se em sua terceira característica.

A primeira das contradições sistêmicas apontadas pelo autor derivaria da atuação de uma elite tecnocrática e muito qualificada, formada para aplicar regras e atuar dentro de um sistema racional, porém, inserida em um contexto em que predomina uma aplicação seletiva e arbitrária das leis. A segunda contradição diz respeito à corrupção e às desigualdades. Estas são crescentes e endêmicas e resultam em parte da discricionariedade concedida a uma burocracia que a utiliza para auferir ganhos financeiros pessoais. Por outro lado, para a legitimação do sistema é necessário manter a corrupção e as desigualdades sob controle.

Posto isso, o autor se questiona acerca da perenidade e da atratividade do capitalismo político. Nesse sentido, lembra-nos que o governo chinês apoia os interesses da burguesia, mas somente na medida que esses interesses não colidem com os objetivos do Estado, ou seja, da 
elite que o dirige. A convivência de múltiplas formas de propriedade e de direitos de propriedade incertos, condições para a existência desse modelo, permite reforçar a tutela da burguesia local pelo Estado. Deste modo, o autor questiona se os capitalistas chineses controlarão num futuro próximo - Estado e, se caso isso vier a acontecer, se eles apoiar-se-ão numa democracia representativa, tal como ocorreu nos Estados Unidos e na Europa.

Quanto à atratividade do capitalismo político, Milanovic destaca que suas regras de funcionamento não são generalizáveis, o que limita as suas possibilidades de transposição para outros países. Por outro lado, a economia chinesa encontra-se hoje, mais do que em qualquer outro período, integrada à economia mundial e que historicamente o país de melhor performance econômica tende a ser copiado pelos demais, independentemente de suas próprias intenções. Adicionalmente, a China emite sinais de que pretende assumir um papel mais ativo no cenário internacional e vender sua experiência pelo mundo ${ }^{8}$, o que serve de legitimação interna do sistema diante da concorrência do capitalismo liberal.

Sem adentrar em uma discussão densa e controversa sobre a natureza do regime econômico chinês, parece-me que a interpretação oferecida pelo autor acerca do papel assumido pelo comunismo nos países asiáticos é semelhante ao desempenhado pelo desenvolvimentismo na América Latina no século passado, semelhança que ele rejeita, frise-se. 0 desenvolvimentismo resultou de uma atuação governamental deliberada de promoção do crescimento econômico e da produtividade liderada pelo setor industrial com o objetivo de encaminhar soluções para os problemas socioeconômicos dos países da região, dentro da institucionalidade do sistema capitalista (FONSECA, 2015). E a luta pela soberania nacional nas

\footnotetext{
8 A influência chinesa se observa com ênfase na América Latina: seja, por exemplo, através de grandes investimentos no setor portuário, como em Chancay, no Peru, em Paranaguá, no Brasil, ou em Lázaro Cárdenas, no México; seja, já num contexto pandêmico, por intermédio do envio de equipamentos sanitários e de doações de tecnologias aos países da região, como sensores de imagem que medem a temperatura dos viajantes em aeroportos (Argentina) e sistemas auxiliares para o diagnóstico da covid-19 em hospitais (Equador e República Dominicana).
} 
decisões econômicas - acrescentamos - sempre esteve presente no pensamento estruturalista latino-americano, ideologia que deu suporte ao desenvolvimentismo aplicado na região.

No capítulo 4, intitulado "Interações entre Capitalismo e Globalização", Milanovic se debruça sobre os principais desafios que se colocam ao capital e ao trabalho em tempos de globalização econômica. 0 autor inicia sua reflexão retomando ideias já presentes em sua obra anterior $^{9}$, ao apresentar a cidadania como um prêmio que confere ao seu detentor uma renda, e como um ativo econômico que pode mesmo ser comercializado ${ }^{10}$.

Como a migração é estimulada pelas acentuadas desigualdades de renda entre os países e levantar barreiras à circulação global das pessoas não é desejável, o autor argumenta que os nacionais tendem a melhor aceitar a imigração quando os trabalhadores estrangeiros não estabelecem residência permanente e não usufruem da totalidade dos benefícios da cidadania. Com efeito, sugere uma redução do prêmio de cidadania dos imigrantes a partir da restrição de seus direitos. Em sua ótica, há um evidente conflito entre, de um lado, o Estado Social dos países ricos, cujo acesso baseia-se na cidadania, e, de outro, a livre circulação de trabalhadores.

A circulação do capital na globalização, por sua vez, é analisada por Milanovic pela ótica das cadeias de valor globais. Em sua visão, atualmente o desenvolvimento de um país passa pela integração aos canais de produção ocidentais, e não por uma desconexão com o mundo rico, conforme ele erroneamente - cumpre destacar - aponta ter sido defendido pelo pensamento estruturalista latino-americano. Acrescenta que a deslocalização da produção permitiu ganhos aos trabalhadores de países mais pobres para os quais a produção se transferiu, em que pese ter fragilizado o poder de negociação dos trabalhadores dos países

\footnotetext{
${ }^{9}$ Ver Milanovic (2016).

${ }^{10} \mathrm{O}$ autor lembra que os ricos podem obter títulos de residência em muitos países sob a condição de efetuar um investimento mínimo definido legalmente.
} 
desenvolvidos e estagnado os salários dos trabalhadores menos qualificados.

O capítulo termina com um alerta para a crescente corrupção mundial, alimentada por um capitalismo hipermercantilizado e globalizado; pela livre circulação internacional de capitais, que favorece a lavagem de dinheiro roubado e a evasão fiscal; e pelo efeito exposição exercido pelos habitantes de países ricos em seus congêneres de países pobres, que muitas vezes diante da impossibilidade de reproduzirem padrões de vida próprios de sociedades mais abastadas, veem-se estimulados a praticar atos de corrupção.

As ideias apresentadas por Milanovic no quarto capítulo são, sem dúvidas, as mais polêmicas do "Capitalismo Sem Rivais". A principal delas refere-se à defesa da redução de direitos econômicos do trabalhador imigrante. A esse respeito, como forma de auxiliar as reflexões dos leitores, questiono: se os trabalhadores imigrantes de países pobres laboram em atividades socialmente úteis aos países ricos receptores, muitas vezes rejeitadas pelos nacionais, como justificar o acesso a um padrão rebaixado de direitos econômicos que os impingem a uma condição de cidadão de segunda classe diante de um trabalhador nacional?

No último capítulo, Milanovic produz reflexões sobre o futuro do capitalismo mundial. Lembra-nos que a busca sistemática e racional pela riqueza não mais se defronta com constrangimentos impostos pela religião e por um contrato social tácito que introjetam nos indivíduos controles ou inibições internas. Diante somente de empecilhos legais, a moral foi externalizada, pelo que o egoísmo e a ambição passam a ditar de forma desmesurada o comportamento individual, florescendo o lado mais sombrio dessas sociedades. Entretanto, não haveria, ao seu ver, alternativa ao capitalismo que não comprometesse a renda e o progresso técnico atualmente existentes e, portanto, o bem-estar de ampla parcela da população mundial. 
O autor identifica na atomização, o fato de todos os bens e serviços estarem à nossa disposição para a compra, em prejuízo da família como responsável pela satisfação de nossas necessidades, e na mercadorização, a transformação máxima de nossos bens e do nosso tempo livre em mercadoria (a Uberização), o verso e o reverso de uma mesma medalha. Como corolário, molda-se um mercado de trabalho extremamente flexível, com as pessoas migrando rapidamente de uma atividade a outra, sem estabelecer relações de emprego minimamente estáveis. Assim, Milanovic mostra-se crítico, mas também resignado com o sucesso do capitalismo hipermercantilizado. A mercantilização de todas as esferas da vida, ressalta, não cumpriu a promessa que nutriu esperanças em pensadores como Montesquieu de que promoveria a benevolência entre desconhecidos. Ao contrário, a atomização esvaziou a vida familiar e a brevidade das interações humanas tornou proibitivo o custo de comportamentos cooperativos, em um contexto fundamentalmente amoral.

Para concluir, o autor apresenta uma reflexão prospectiva acerca do futuro do capitalismo mundial a partir do embate entre o capitalismo liberal e o capitalismo político enquanto alternativas de desenvolvimento aberta aos países atualmente. Na medida que o primeiro apresentaria uma vantagem "natural", posto que um sistema político democrático estaria inscrito na configuração do sistema, as vantagens do capitalismo político, a exemplo de um maior dinamismo econômico, seriam instrumentais, necessitando de constante demonstração para reafirmar a sua superioridade. Os pontos negativos do capitalismo político residiriam nas suas dificuldades para mudar de rumo pela ausência de controles democráticos, e na tendência intrínseca de crescimento da corrupção pela inexistência de um Estado de direito.

No final das contas, argumenta Milanovic, a evolução do capitalismo dependerá de seu modelo meritocrático liberal ser capaz de se aproximar da configuração de um capitalismo popular, onde os rendimentos do capital seriam menos concentrados, as desigualdades de rendimentos menos acentuadas e a mobilidade intergeracional assegurada. Caso 
contrário, aproximar-se-ia de um capitalismo de feição nitidamente plutocrática e, portanto, mais aparentado ao capitalismo político. Eis a encruzilhada na qual o capitalismo hoje se encontra.

"Capitalismo Sem Rivais" tece uma interpretação do capitalismo atual que oscila entre tons laudatórios, críticos e resignados. Milanovic brinda-nos com uma análise que, ainda que polêmica em muitos pontos, é pouco usual pela forma como transita entre diversas áreas do conhecimento científico, além da economia, formação acadêmica inicial do autor. Ele opta ainda por não se acomodar no terreno das soluções habituais ou da interpretação puramente apologética da realidade. Assim, não é preciso concordar com todos os argumentos presentes no livro para considerá-lo uma leitura importante para a compreensão do mundo em que vivemos e para a reflexão crítica dos rumos que atualmente ele trilha, especialmente se considerarmos as suas regiões mais pobres, como a América Latina, historicamente envolvida com os problemas abordados pelo autor na presente obra.

\section{Referências}

AMABLE, Bruno. Les cinq capitalismes : diversité des systèmes économiques et sociaux dans la mondialisation. Paris: Éditions du Seuil, 2005.

FONSECA, Pedro Cezar. Desenvolvimentismo: a construção do conceito. Texto para Discussão, $\mathbf{n}^{\circ}$ 2103. Brasília: Rio de Janeiro: IPEA, 2015. Disponível em: https://www.ipea.gov.br/portal/images/stories/PDFs/TDs/td_2103.pdf>. Acesso em: 28 mai. 2021.

MILANOVIC, Branko. A desigualdade no mundo: uma nova abordagem para a era da globalização. Coimbra: Actual Editora, 2016.

PIKETTY, Thomas. Capital e ideologia. Lisboa: Temas e Debates - Círculo de Leitores, 2020.

RAMAUX, Christophe. L'état social: pour sortir du chaos néolibéral. Paris: Mille et Une Nuits, 2012.

STIGLITZ, Joseph. Pessoas, poder e lucro: capitalismo progressista para uma era de descontentamento. Lisboa: Bertrand Editora, 2019. 